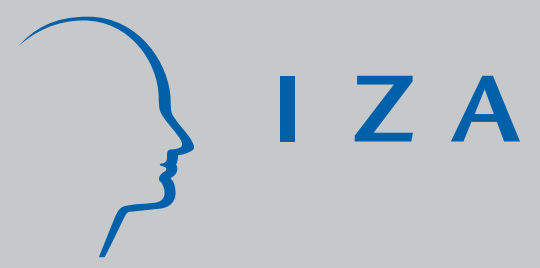

IZA DP No. 310

Human Capital Accumulation, Education and Earnings Inequality

Uwe Sunde

J une 2001 


\title{
Human Capital Accumulation, Education and Earnings Inequality
}

\author{
Uwe Sunde \\ Universitat Pompeu Fabra, Barcelona \\ and IZA, Bonn \\ Discussion Paper No. 310 \\ June 2001 \\ IZA \\ P.O. Box 7240 \\ D-53072 Bonn \\ Germany \\ Tel.: +49-228-3894-0 \\ Fax: +49-228-3894-210 \\ Email: iza@iza.org
}

This Discussion Paper is issued within the framework of IZA's research area The Future of Work. Any opinions expressed here are those of the author(s) and not those of the institute. Research disseminated by IZA may include views on policy, but the institute itself takes no institutional policy positions.

The Institute for the Study of Labor (IZA) in Bonn is a local and virtual international research center and a place of communication between science, politics and business. IZA is an independent, nonprofit limited liability company (Gesellschaft mit beschränkter Haftung) supported by the Deutsche Post AG. The center is associated with the University of Bonn and offers a stimulating research environment through its research networks, research support, and visitors and doctoral programs. IZA engages in (i) original and internationally competitive research in all fields of labor economics, (ii) development of policy concepts, and (iii) dissemination of research results and concepts to the interested public. The current research program deals with (1) mobility and flexibility of labor markets, (2) internationalization of labor markets and European integration, (3) the welfare state and labor markets, (4) labor markets in transition, (5) the future of work, (6) project evaluation and (7) general labor economics.

IZA Discussion Papers often represent preliminary work and are circulated to encourage discussion. Citation of such a paper should account for its provisional character. 
IZA Discussion Paper No. 310

June 2001

\title{
ABSTRACT \\ Human Capital Accumulation, Education and Earnings Inequality*
}

This paper attempts to add to the understanding of the causes for the differing recent developments in inequality in OECD countries. The similarity of shocks and technological changes affecting these countries suggests that interactions of these shocks and countryspecific institutions are responsible for the diverging inequality patterns. The paper suggests a channel complementary to those investigated in recent contributions, focusing on the impact of education. A microfoundation of human capital formation is proposed, emphasizing heterogeneity of individuals and multidimensionality of human capital. The reactions in individual behavior triggered by technological change are crucially affected by the education system and are shown to be responsible for the divergent developments in inequality.

JEL Classification: E20, J30, J31, O30

Keywords: Inequality, ability biased technological change, education system, human capital formation

\author{
Uwe Sunde \\ IZA \\ PO Box 7240 \\ 53072 Bonn
}

Germany

Tel.: +492283894533

Fax: +492283894210

Email: sunde@iza.org

\footnotetext{
* I am very grateful to Antonio Cabrales, Antonio Ciccone and Adriana Kugler for many useful comments. Moreover, I wish to thank Matteo Cervellati, Quentin Dupriez, René Fahr, Matthias Messner, Wendelin Schnedler, Sandro Secchi and seminar participants at UPF for suggestions and critical comments. All errors are my own. Comments Welcome.
} 


\section{Introduction}

One of the most heavily studied economic phenomena of recent years is the pattern of earnings inequality in developed countries. A growing literature deals with the differences in inequality across countries and tries to shed light on the reasons why some developed countries experienced a sharp increase in earnings inequality, while inequality remained roughly constant or even declined in other countries. ${ }^{1}$ To pick two frequently mentioned examples, between and within group earnings inequality increased strongly in the US, whereas in Germany inequality between and within groups remained constant at comparatively low levels or even decreased in the same period. ${ }^{2}$

According to the bulk of the literature, changes in inequality were driven by technological shocks which increased the relative demand for part of the labor force, namely skilled and educated labor (computerization), decreased the relative demand for low skilled labor (globalization), and by the flexibilization of labor market institutions. ${ }^{3}$ Empirical evidence ${ }^{4}$ however suggests that developed countries had to cope with virtually identical shocks, so differences in the levels of inequality and in their development are explained with differences in country specific institutions interacting with the driving shocks. ${ }^{5}$

The model presented in this paper elaborates a mechanism complementary to the many discussed in the literature which are based on institutions like minimum wages, unemployment benefit systems or central bargaining. It seems that these explanations fail to explain some aspects of the question of inequality, and some authors like Abraham and Houseman (1993), Nickell and Bell (1996), Nickell (1997) and recently Freeman and Schettkat (2001) have indicated that a crucial, but so far neglected, factor to understand the distinct development might be differences in educational systems.

While the argument is often used informally, no effort has been made so far to provide a theoretical foundation of the interaction of the schooling system, human capital accumulation and inequality. This paper lines out a potential explanation why the educational system might matter, and why the human capital distribution is more compressed in some countries. Education is viewed as a production process that transforms individual endowments into human capital. Endowments as well as human capital have several dimensions. After producing the desired varieties of human capital using their heterogeneous endowments, individuals sell their human capital

\footnotetext{
${ }^{1}$ Compare Freeman (1999) and Katz and Autor (1999) for detailed surveys and references for empirical evidence.

${ }^{2}$ Gottschalk and Smeeding (1997), Blanchflower and Slaughter (1999), Freeman (1999), Telhado-Prereira and Silva-Martins (2000).

${ }^{3}$ Katz (1999), and Katz and Autor (1999).

${ }^{4}$ Berman, Bound and Machin, 1998, and Machin and Van Reenen, 1998).

${ }^{5}$ See Katz and Autor(1999), and Nickell and Layard (1999), and Blanchard and Wolfers (2000) for an overview over the explanations in the literature.
} 
on the labor market. Abstracting from other institutional differences, it will be shown that the structure of the education system plays the crucial role for the effects of the shocks mentioned on between and within group inequality.

The paper is a complement to models focusing on the structure of the shocks driving changes in inequality and the channels through which this happens. Most of the literature, like the model by Theshmar and Thoenig (2000), takes the structure of labor supply as given and fixed, and assume labor to be heterogeneous and divided into skilled and unskilled, which themselves are largely homogenous groups, and are therefore only suited for explaining developments in between group inequality. ${ }^{6}$ The model presented below focusses on the endogenous determination of the structure of human capital offered on the labor market. Therefore, it extends these models by endogenously specifying labor supply and analysing changes in the structure of labor given the education system. ${ }^{7}$ The model is very much in the spirit of Galor and Moav (2000) in allowing to analyze aspects of between and within group inequality, but it goes further in explicitly incorporating an education process, giving rise to cross country differences in the reaction to identical shocks. Moreover, shocks are explicitly modeled to affect the labor demand side, giving a more precise meaning to the notion of why technological changes should be 'ability biased' and taking general equilibrium effects into account.

Section 2 lays down a simple model in which ex ante heterogeneous individuals decide upon the structure of the human capital they supply on the labor market. The main results regarding inequality are presented in section 3 . Section 4 analyzes the channels through which education systems generate differing inequality results across countries, even with an otherwise identical structure of the economy and the same driving shocks. Section 5 discusses the empirical relevance of the theoretical framework, and section 6 concludes.

\footnotetext{
${ }^{6}$ In the paper by Theshmar and Thoenig (2000), prices for heterogeneous types of labor are driven by the interrelation of the rate of creative destruction, market volatility, and the organizational choices of firms. Moebius (2000) provides a similar argument when explaining secular changes in organizations and market structure. Models investigating within group inequality include e.g. Galor and Tsiddon (1997), Acemoglu (1998,1999), Aghion, Howitt and Violante (2000), Caselli (1999).

${ }^{7}$ An early model treating education as production process by Ben-Porath (1967) concentrates on the dynamically optimal human capital accumulation path for an individual. Kim (1989) presents a related model of human capital accumulation where individuals face a trade-off between depth and breadth of human capital they want to acquire. However, the paper's focus is mainly on the quality of the match and how it is affected by market size. Helpman and Rangel (1998) focus on the interaction between schooling and on-the-job learning in investigating workers' education and sector decision in the presence of technological progress that either complements or substitutes education.
} 


\section{A simple Model of Human Capital Formation}

In what follows, individuals supply labor and firms produce output using labor and sell the output on perfect markets in a small open economy. The model is static. ${ }^{8}$

\section{$2.1 \quad$ Individuals}

The economy is populated by a unit mass continuum of individuals $j$, with $j \in[0,1]$. In order to make a living, individuals have to generate income by selling human capital $H_{j}$ on the labor market. Human capital is not tradable, that is it is incorporated in its owner and only he can sell it. To keep things as simple as possible without eradicating the complex multidimensionality completely, human capital is viewed as two-dimensional. To fix ideas, one can think of human capital as applied knowledge that allows a worker to perform a task with certain efficiency, precision or speed, or to use other inputs or tools in the given production process in a cost-saving manner. Loosely speaking, by "specializing" on a given task, productivity can be increased, so this depth of knowledge allows to handle a technology more efficiently. ${ }^{9}$ However, it seems obvious that in a changing world, also the capability of adapting to new technological environments, changing tasks and responsibilities or switching to the production of completely different final outputs is an important component of human capital embodied in employees. This type of human capital is called abstract knowledge. ${ }^{10}$ Following the examples given, applied knowledge will also be called intensive and abstract knowledge extensive human capital, and will be denoted $I$ and $E$, respectively. ${ }^{11}$ Human capital is a vector $H_{j}=\left(I_{j}, E_{j}\right)$.

Individuals do not own human capital by nature. Rather, they have to acquire it in a production process called education. As inputs in this process they use all endowments they have at their disposal. Again abstracting from the complexity found in reality, there are only two sorts of endowments in the model economy. One is called schooling $s_{j}$, which is not to be confused with the education process. Schooling is provided at zero cost by some authority (the "government") and is the same for all members of society, so $s_{j}=s, \forall j$. Intuitively, schooling can be interpreted as the education infrastructure, the provision of teachers, schools, universities and the availability of books, computers etc.. For example, every individual is entitled to go to school or

\footnotetext{
${ }^{8}$ The model can be easily put into a dynamic overlapping generations framework similar to Galor and Moav (2000) without affecting any of the results.

${ }^{9}$ Essentially, this is the type of human capital that stands behind increasing returns technologies like in Theshmar and Thoenig (2000) and Moebius (2000).

${ }^{10}$ Using the definition of Hassler and Rodriguez-Mora (2000), abstract knowledge helps to solve a problem never faced before by resorting to known abstract concepts.

${ }^{11}$ This termination follows Kim (1989).
} 
university for a certain number of years, to use libraries etc. ${ }^{12}$ Since there are no explicit costs for schooling, every individual will utilize his entire endowments in what follows.

In reality, individuals and their human capital are heterogeneous. Some people adapt faster to changes in their environments, others are more productive in certain tasks than their mates, even though they went together through the same schools. In order to capture this fact, it is assumed that members of society are heterogeneous with respect to their second endowment, innate ability $a_{j}$. This can be thought of as cognitive ability, intelligence, or learning capacity. For simplicity, assume that ability takes on some positive real value between zero and $\bar{a}$, that is $a_{j} \in[0, \bar{a}]$, and is distributed uniformly. ${ }^{13}$

The fundamental problem for an individual is therefore to find the mix of abstract and applied knowledge (or extensive and intensive human capital) $E$ and $I$ to offer on the labor market which maximizes his income. Individuals use all endowments at their disposal, schooling and ability, to produce the two components of human capital. In the remainder of the paper, it will be assumed for simplicity that both types of human capital are produced with separate production functions, each employing both inputs in any desired combination. ${ }^{14}$ The only assumption that is crucial for the results of the paper is that both technologies differ in their relative use of inputs, while the production processes are technologically the same for all individuals in the economy.

In what follows, it is assumed that the production of extensive human capital is relatively more ability-intensive, while intensive human capital is more schooling-intensive. Intuitively, ability helps in adopting to changing environments more than schooling does. ${ }^{15}$ On the other hand, concrete and directed schooling is relatively more efficient in creating productivity and applied knowledge in a certain task or field of tasks than ability. Individuals therefore face a trade-off between using what they have at disposal for one or the other purpose.

\footnotetext{
${ }^{12}$ The assumption of homogeneous provision of schooling will be relaxed below. However, it is not as unrealistic as it might first seem: Educational expenditure per capita is roughly comparable across developed countries. Compare OECD (2000a).

${ }^{13}$ The assertion of an upper bound of intelligence $\bar{a}$ is made due to the assumption of a uniform distribution of ability. However, the somewhat unrealistic assumption of a uniform distribution can be relaxed making it unnecessary to specify à without changing the results.

${ }^{14}$ This is just a simplification and could easily be relaxed, assuming e.g. a technology using two inputs to produce two outputs simultaneously. It is also not essential whether constant, increasing or decreasing returns to either of the inputs are assumed, as is shown in an Appendix available from the author upon request.

${ }^{15}$ Hassler and Rodriguez-Mora (2000) claim that ability or "intelligence" is what matters for adapting to new situations or technologies. In the present model, extensive human capital is the necessary tool, which is in turn more closely linked to ability than to schooling.
} 


\subsection{Human Capital Formation}

By assumption, individual endowments cannot be traded, so every individual $j$ faces the constraints $a_{j}=a_{j E}+a_{j I}$ and $s_{j}=s_{j E}+s_{j I}=s$, where $E$ denotes abstract knowledge (extensive h.c.) and $I$ applied knowledge (intensive h.c.). In the process of education, individuals can transform their endowments into human capital of the form of abstract and applied knowledge. For the moment, assume that an individual cannot produce both simultaneously, but has to decide to produce one of the two exclusively. ${ }^{16}$ For simplicity, let the educational technologies be linear. In an appendix available from the author, it is shown that all results from this linear set-up hold for non-linear technologies with decreasing marginal returns and simultaneous creation of both types of human capital.

$$
\begin{gathered}
E_{j}=\alpha a_{j E}+(1-\alpha) s_{E} \\
I_{j}=\beta a_{j I}+(1-\beta) s_{I}
\end{gathered}
$$

with $\alpha, \beta \in(0,1)$ and the following assumptions on the parameters: ${ }^{17}$

Premise 1. $\alpha>\beta$, and let $\alpha>(1-\alpha)$.

Premise 2. $\frac{\alpha}{\beta}>\frac{p_{I}}{p_{E}}$, where $p_{E}$ is the price paid for (a unit of) extensive human capital on the labor market, and $p_{I}$ is the price for intensive human capital.

Premise 3. $\bar{a}>s$.

These premises only reflect the mentioned differences between technologies with respect to their relative use of inputs: Ability has a higher marginal productivity in $E$-production, and this technological feature also translates into higher marginal revenue productivity (that is that, for the moment, price levels do not converse the technological property in terms of revenue, which is the relevant decision parameter). Additionally, some individuals have "relatively high ability" (with $a_{j}>s$ ) and some "relatively low ability" (with $a_{j}<s$ ). ${ }^{18}$

An individual's decision problem is to find the allocation of individual endowments of schooling and ability in the production of extensive and intensive human capital that maximizes income, that is revenues from selling human capital on the labor market. For the decision, $p_{E}$ and $p_{I}$ are taken as given. The revenues can be graphed as a function of ability $a_{j}$, as is

\footnotetext{
${ }^{16}$ The case of simultaneous production is discussed below.

${ }^{17}$ The assumption that $\alpha, \beta \in(0,1)$ is made to make the example more comparable to the full model developed in the appendix, where $\alpha$ and $\beta$ are the income shares of ability in the respective educational sectors. For the linear model, this assumption is not essential and can easily be relaxed. See below.

${ }^{18}$ Premise 3 is only necessary as a consequence of the assumption that ability's and schooling's marginal productivities are inversely related (i.e. $\alpha$ and $(1-\alpha)$, respectively). If schooling had a parameter unrelated to $\alpha$, that is if e.g. $E=\alpha a_{j E}+\zeta s_{E}$, the premise would be redundant.
} 
done in Figure 1. Individuals endowed with high ability can earn a higher income by producing extensive human capital while those gifted with little ability fare better by selling intensive human capital. The ability level $a^{*}$ at which revenues for extensive and intensive human capital are identical, $p_{E} E(a)=p_{I} I(a)$, can be calculated to be:

$$
a^{*}=\frac{\left(p_{I}(1-\beta)-p_{E}(1-\alpha)\right)}{p_{E} \alpha-p_{I} \beta} s .
$$

Individuals produce the variety of human capital which promises higher revenues, so those of ability intensities lower than the threshold $a^{*}$ choose to acquire applied knowledge, the others transform their endowments into abstract knowledge. The threshold is increasing in $p_{I}$ and decreasing in $p_{E} \cdot{ }^{19}$ Individual income can then be written as

$$
y_{j}=p_{E} E_{j}+p_{I} I_{j}
$$

while every individual produces only one or the other type of human capital.

The total supply of human capital is obtained by aggregating up extensive and intensive human capital over the entire population:

$$
\begin{gathered}
I=\int_{0}^{a^{*}} I\left(a_{j}\right) d j=\frac{\beta}{2} a^{* 2}+(1-\beta) s a^{*} \\
E=\int_{a^{*}}^{\bar{a}} E\left(a_{j}\right) d j=\frac{\alpha}{2}\left(\bar{a}^{2}-a^{* 2}\right)+(1-\alpha) s\left(\bar{a}-a^{*}\right)
\end{gathered}
$$

The ratio of the two gives the relative supply of extensive to intensive human capital:

$$
\left(\frac{E}{I}\right)_{S}=\frac{\frac{\alpha}{2}\left(\bar{a}^{2}-a^{* 2}\right)+(1-\alpha) s\left(\bar{a}-a^{*}\right)}{\frac{\beta}{2} a^{* 2}+(1-\beta) s a^{*}}
$$

It is straightforward to show that $\frac{\partial E}{\partial a^{*}}<0, \frac{\partial I}{\partial a^{*}}>0$, and $\frac{\partial(E / I)_{S}}{\partial a^{*}}<0$. Since the threshold $a^{*}$ in turn depends on the (relative) prices of extensive and intensive human capital, so does the size of their aggregate supplies. In particular, from eq.(3) and from footnote 19 it can be inferred that $\frac{\partial a^{*}}{\partial\left(p_{E} / p_{I}\right)}<0$, because for the individual only relative prices matter. This means that an increase in $\left(p_{E} / p_{I}\right)$ is in its qualitative effects on individual behavior equivalent to an increase in $p_{E}$ with $p_{I}$ constant (or a fall in $p_{I}$ with $p_{E}$ constant).

\footnotetext{
${ }^{19}$ Since

$$
\frac{\partial a^{*}}{\partial p_{E}}=\frac{-(1-\alpha)\left(p_{E} \alpha-p_{I} \beta\right)-\left[p_{I}(1-\beta)-p_{E}(1-\alpha)\right] \alpha}{\left(p_{E} \alpha-p_{I} \beta\right)^{2}}<0
$$

and

$$
\frac{\partial a^{*}}{\partial p_{I}}=\frac{(1-\beta)\left(p_{E} \alpha-p_{p} \beta\right)+\left[p_{I}(1-\beta)-p_{E}(1-\alpha)\right] \beta}{\left(p_{E} \alpha-p_{I} \beta\right)^{2}}>0
$$
}


Ceteris paribus, a rise in the (relative) price of extensive human capital increases the supply of extensive human capital (since the threshold decreases, therefore inducing more individuals to acquire extensive instead of intensive human capital). Hence, also the relative supply of extensive to intensive human capital is increasing in the relative prices:

$$
\frac{\partial(E / I)_{S}}{\partial\left(p_{E} / p_{I}\right)}>0
$$

\subsection{Firms and Labor Demand}

Firms produce their single final output $Y$ using human capital in the form of extensive and intensive human capital. For simplicity, they face a given final output price $p_{Y}$ which is normalized to 1 on the competitive international output market, and they can sell whatever they produce with the human capital they are supplied with. Hence, their objective is to maximize profits given output price and input supply. Also for simplicity, there are no divisibility problems in the employment relationships between agents and firms, the labor market is frictionless and always clears, so there is no unemployment. Due to symmetry, the results will not change if only one representative firm is assumed to act on output and labor markets. Let this firm produce output using only human capital according to a generic CES production function of the form: ${ }^{20}$

$$
Y=\left[\gamma^{\frac{1}{\theta}} E^{\frac{\theta-1}{\theta}}+(1-\gamma)^{\frac{1}{\theta}} I^{\frac{\theta-1}{\theta}}\right]^{\frac{\theta}{1-\theta}}
$$

where $\theta$ is the elasticity of substitution between extensive and intensive human capital, and $\gamma$ is the share of extensive human capital in output production which is determined exogenously. The necessary conditions of the profit maximization problem imply a demand relation for the two components of human capital as a function of their price ratio:

$$
\left(\frac{E}{I}\right)_{D}=\left(\frac{\gamma}{1-\gamma}\right)\left(\frac{p_{E}}{p_{I}}\right)^{-\theta}
$$

\subsection{Labor Market Equilibrium}

The equilibrium is characterized by the price ratio $\left(p_{E} / p_{I}\right)$ for which the input ratio supplied equals the one demanded by firms. Because of the nonlinearity of the equilibrium relationship in the price ratio, it is not possible to find a closed form solution for the equilibrium price. However, as a consequence of the setup, the model has a unique equilibrium, since from eq.(10) (eq.(7)) demand (supply) is continuous and monotonically decreasing (increasing) in the price ratio.

\footnotetext{
${ }^{20}$ This specification follows Nickell and Layard (1999) and Acemoglu (2001) in allowing a simple representation for universal changes in relative labor demand.
} 
The results of the model are driven by exogenous changes in the shares of extensive and intensive human capital in final output production, that is $\gamma$, which will be discussed in the next section. For the comparative statics experiments studied, it is enough to have an understanding of the relationship between the technological parameter $\gamma$ and the relative prices of extensive and intensive human capital. In order to find the equilibrium relationship between $\gamma$ and $\left(p_{E} / p_{I}\right)$, the implicit function theorem is applied. To do this, the term $G=\left(\frac{E}{I}\right)_{D}-\left(\frac{E}{I}\right)_{S}=0$ is derived partially with respect to $\gamma$ and $\left(p_{E} / p_{I}\right)$, since the negative ratio of these partial derivatives gives the desired implicit relation. Straightforward calculations reveal that, for all possible parameter constellations, the implicit relation is positive in equilibrium: ${ }^{21}$

$$
\frac{d\left(p_{E} / p_{I}\right)}{d \gamma}>0
$$

Hence, if due to one of the reasons discussed in the next section, the share of versatility in final output production $\gamma$ increases, the relative price of versatility goes up as well in equilibrium.

Note that, if in this formulation a shock increases the share of abstract knowledge in final output production, it thus increases the price of abstract knowledge $p_{E}$. The opposite happens to the share and thus the price of applied knowledge: it decreases. This is, at least empirically, an undesirable feature of the model. ${ }^{22}$ However, it is just an innocuous simplification in order to keep things a simple as possible. By introducing a shift parameter (like TFP) which grows constantly over time in eq. 9, the discussed price changes are no more absolute, but relative as both factor prices grow over time, albeit at different rates depending on $\gamma$, which reconciles the model's behavior again with the empirical evidence.

\section{Changes in Earnings Inequality}

The set-up presented in the last section lends itself readily to a comparative static analysis of the impact of technological shocks on income inequality. This section describes the nature of the shocks considered, and singles out the effect of the shocks on the equilibrium allocations and individual incomes.

\subsection{Forces Driving Changes in Inequality}

The model tries to line out a connection between inequality and changes in the relative demand for different types of human capital, which are more

\footnotetext{
${ }^{21}$ Since: $\frac{\partial G}{\partial \gamma}=\frac{1}{(1-\gamma)^{2}}\left(\frac{p_{E}}{p_{I}}\right)^{-\theta}>0$ and $\frac{\partial G}{\partial\left(p_{E} / p_{I}\right)}=\frac{\partial(E / I)_{D}}{\partial\left(p_{E} / p_{I}\right)}-\frac{\partial(E / I)_{S}}{\partial\left(p_{E} / p_{I}\right)}<0$.

${ }^{22}$ Note that this effect is also present in the models of Caselli (1999) and Galor and Moav (2000).
} 
subtle than plain "skill bias". It is therefore deliberately vague and agnostic about the actual causes of these changes. One can think of several reasons for shocks to the relative shares of extensive and intensive human capital, $\gamma$.

Technological changes like increasing computerization of all sorts of occupations or the invention and subsequent adoption of new General Purpose Technologies (compare Helpman (1999), Aghion and Howitt (1998) and Aghion, Howitt and Violante (2000)) might increase the role played by abstract knowledge in the production process and in turn reduce the role of (manual or mechanical) applied knowledge.

Organizational changes and restructuring efforts have received increasing interest recently (compare Aghion et al. (1999) for an overview and Lindbeck and Snower (2000) for a recent model). The argument is that firms move from Tayloristic to more holistic workplace structures, including flatter hierarchies, more team-based working, and involving higher individual responsibilities, so that individual versatility and intellectual flexibility become ever more important for firms. Thesmar and Thoenig (2000) provide an endogenous growth model in which growth, market volatility and organizational choice affect each other, increasing the demand for skilled labor if organizations are flatter. Moebius (2000) provides a model of secular technological change, in which the structure of product markets, in particular uncertainty and unpredictability, induce firms to adjust their organizational structure and thus their skill requirements.

Increasing levels of interregional and international trade and higher openness might lead to globalization pressures along the lines of traditional trade models, that is a reduction in the importance of capital and productivity related human capital, favoring more "innovational", abstract knowledge biased human capital.

One could come up with many more examples why the share of extensive human capital could go up (and have gone up in reality in recent years). On the other hand, the model is also flexible enough to encompass "Tayloristic" shocks, like the introduction of the assembly line and more standardized production processes, leading to an increase in the share of intensive human capital (fall in $\gamma$ ).

\subsection{Changes in Inequality}

In order to make any statements on inequality, let inequality be the ratio of total incomes earned by the group of individuals endowed with the highest ability (above a threshold of $(1-h) \%$ of the maximal ability $\bar{a}$, henceforth called high-income class) to those earned by the group of lowest ability (below $l \bar{a}$, the low-income class): ${ }^{23}$

\footnotetext{
${ }^{23}$ It is clear from the set-up that higher ability necessarily translates into higher income. The measure is chosen for explanatory reasons and because it is a general formulation
} 


$$
R=\frac{\int_{h \bar{a}}^{\bar{a}} y_{j} d a_{j}}{\int_{0}^{l \bar{a}} y_{j} d a_{j}}
$$

For the sake of simplicity, assume for the moment that the thresholds $l$ and $(1-h)$ are such that all members of the low income group supply applied, all members of the high income group supply abstract knowledge. ${ }^{24}$ The inequality measure then simplyfies to:

$$
R=\frac{\int_{h \bar{a}}^{\bar{a}} p_{E} E_{j} d a_{j}}{\int_{0}^{l \bar{a}} p_{I} I_{j} d a_{j}}
$$

It is worthwhile noting that in the model at hand "within" and "between" group inequality in the conventional sense are equivalent, since the schooling endowment is homogeneous. The groups differing in the type of human capital they produce are not different in the sense of "high skilled" and "low skilled", and therefore the groups in the model are not comparable with the concepts of groups in the conventional sense (skilled and unskilled), which is also used in empirical studies. If anything, the model presented lends itself more naturally to the explanation of within group inequality. However, if groups are defined in the ability space, the results to be shown will be qualitatively the same for within and between group inequality.

Now the ground is laid to perform the comparative static exercises that lead to the central results of the paper: First, consider an increase in the share of extensive human capital in output production. As a consequence, the (relative) price of extensive human capital will increase in equilibrium, triggering a supply reaction in the form of a decreased threshold value $a^{*}$. This means that some individuals who otherwise would have acquired applied knowledge, now produce abstract knowledge. This first result can be summarized:

Proposition 1 An increase in the share of extensive human capital in final aoutput production, $\gamma$, has the following effects:

- In equilibrium, the relative price of extensive to intensive human capital, $\left(p_{E} / p_{I}\right)$, is higher.

- The total supply of extensive human capital is higher, the total supply of intensive human capital is lower.

similar to the measures used in empirical work. The choice of the inequality measure is not crucial for the results of the model, which could be shown with any common measure, at the cost of some mathematical complications.

${ }^{24}$ This assumption is made for expository convenience. It will become clear that how the thresholds are chosen does not affect the results (and hence it is not essential whether also applied knowledge producers enter the high income class, or abstract knowledge producers the low income class). 
Proof. The first point follows from eq. (11). For the second point, remember that from footnote 19 and eq. (8): $\frac{\partial a^{*}}{\partial\left(p_{E} / p_{I}\right)}<0$. The claim follows from the fact that because of this threshold shift, some individuals produce extensive instead of intensive human capital, but not the other way around. QED.

The effect of this on inequality is twofold: Due to the price effects, suppliers of extensive human capital gain relative to those supplying intensive human capital as they receive more for what they have to offer. Second, due to the shift in the threshold, some individuals switch to extensive human capital since they can increase their income by doing that. However, note that this means that individuals endowed with high ability and thus high incomes benefit more from the change in $\gamma$ since they are those who supply extensive human capital. In other words, an increase in the (relative) price of abstract knowledge increases inequality by triggering more production of abstract knowledge which is more ability intensive, thereby accentuating heterogeneity in the society:

Proposition 2 An increase in $\gamma$ increases inequality.

Proof. Note that

$$
\begin{aligned}
\frac{\partial R}{\partial\left(p_{E} / p_{I}\right)} & =\frac{\partial}{\partial\left(p_{E} / p_{I}\right)} \frac{\int_{h \bar{a}}^{\bar{a}} p_{E} E_{j} d a_{j}}{\int_{0}^{l \bar{a}} p_{I} I_{j} d a_{j}} \\
& =\frac{\partial}{\partial\left(p_{E} / p_{I}\right)} \frac{p_{E}}{p_{I}} \frac{\int_{h \bar{a}}^{\bar{a}} E_{j} d a_{j}}{\int_{0}^{l \bar{a}} I_{j} d a_{j}} \\
& =\frac{\int_{h \bar{a}}^{\bar{a}} E_{j} d a_{j}}{\int_{0}^{l \bar{a}} I_{j} d a_{j}}>0
\end{aligned}
$$

To keep track of changes in the structure of human capital supply, consider the measure of eq.(12) instead of eq. (13). If the threshold $a^{*}>h \bar{a}$, from Prop. 1 and footnote $19, a^{*}$ decreases, thus increasing the income of switchers from applied to abstract knowledge, so inequality increases. If $a^{*}<l \bar{a}, a^{*}$ decreases, so members of the low income class benefit from the increase in $\gamma$, but due to their smaller endowments by less than those in the high income class, so inequality increases unambiguously. QED.

\section{The Impact of Education}

As the title suggests, the aim of the paper is to show how the education system affects the inequality outcome. In this section, two different channels are examined through which this might happen. They are complementary explanations and can both be justified empirically and intuitively. In both cases, the results from the preceding section are taken as a benchmark. 


\subsection{Heterogeneity in the Provision of Schooling Endowments}

Consider an economy in which schooling $s_{j}$ is provided inequally to individuals. For simplicity, let there be two levels of schooling provision, high $\left(s^{H}\right)$ and low $\left(s^{L}\right)$ with $s^{H}>s>s^{L}$, equivalent to good (rich) and bad (poor) neighborhoods or states providing schooling endowments. ${ }^{25}$ Further, assume that these are distributed uniformly over the population, and that the average schooling endowment per individual is the same as in the benchmark case. Ceteris paribus, the decision parameters remain the same as above, leading to different education decisions for people of identical ability - depending on their schooling endowment. In particular, take two clones of identical ability: The one endowed with better schooling $\left(s^{H}\right)$ faces a higher threshold for producing abstract knowledge. This means that, under good schooling provision, some individuals produce applied knowledge, while they would produce abstract knowledge if they would be endowed with poor schooling. However, those with high schooling earn higher incomes in any case, since their overall endowments are higher. The effects on inequality are easily deducted: the results from above remain true. However, since highly able people gifted with good schooling endowments are the earners of the highest incomes, while the least able endowed with bad schooling are those earning the lowest incomes, it is intuitive, that inequality is higher if schooling provision is heterogeneous. ${ }^{26}$

Proposition 3 Income inequality is higher if schooling is provided more inequally.

Proof. Note that the earners of highest incomes own the highest endowments, and vice versa. Let $E_{j}^{H}$ and $E_{j}$ be extensive human capital produced by individual $j$ using $s^{H}$ or $s$, respectively, and $I_{j}^{L}\left(I_{j}\right)$ intensive human capital using $s^{L}(s)$. Since $s^{H}>s>s^{L}, E_{j}^{H}>E_{j}$ and $I_{j}^{L}<I_{j}$ Without loss of generality, choose $l$ and $h$ such that $R_{H L}=\frac{p_{E}}{p_{I}} \frac{\int_{h \bar{a}}^{\bar{a}} E_{j}^{H} d a_{j}}{\int_{0}^{l a} I_{j}^{L} d a_{j}}$. But then: $R_{H L}>R=\frac{p_{E}}{p_{I}} \frac{\int_{h \bar{a}}^{\bar{a}} E_{j} d a_{j}}{\int_{0}^{\bar{a}} I_{j} d a_{j}}$. QED.

Proposition 4 The increase in inequality prompted by an increase in the share of extensive human capital, $\gamma$, is larger in the economy in which schooling is provided less equally to the population.

Proof. Note that from Prop. 1 and eq. (11), $\frac{\partial R}{\partial \gamma} \propto \frac{\partial R}{\partial\left(p_{E} / p_{I}\right)}$. But

$$
\frac{\partial R_{H L}}{\partial\left(p_{E} / p_{I}\right)}=\frac{\int E_{j}^{H} d a_{j}}{\int I_{j}^{L} d a_{j}}>\frac{\int E_{j} d a_{j}}{\int I_{j} d a_{j}}=\frac{\partial R}{\partial\left(p_{E} / p_{I}\right)} \text { QED. }
$$

\footnotetext{
${ }^{25}$ In what follows, also symmetry is assumed, that is: $s^{H}-s=s-s^{L}$.

${ }^{26}$ For a graphical illustration, compare Fig. 2.
} 
Clearly, these results hinge on the assumption about the structure of heterogeneity in schooling provision. Arguably, uniform distribution of schooling is an innocuous assumption. However, it is intuitively clear that the more realistic assumption of a positive correlation of ability and schooling endowment (e.g. ghettos versus promotion of highly talented in elite institutions) would even reinforce the effects described above.

\subsection{Education Technology}

Another channel through which education affects labor market outcomes is more subtle: What makes the difference is how endowments are transformed into human capital. This "how" refers to more qualitative differences between education systems like curricula, the type and variety of schools and courses available and the number of alternative educational carreers an individual can choose from. To illustrate these differences, the stylized US and the German systems are discussed in the following subsection.

In terms of the model, differences in the way how ability and schooling are transformed into intensive and extensive human capital are introduced in the most simple way, namely by assigning different values to the technology parameters. To be more precise, denote the parameters of this modified economy with a prime ${ }^{27}$, and make the assumptions that

Assumption 1. $\alpha^{\prime}<\alpha$, and

Assumption 2. $\left(\alpha^{\prime}-\beta^{\prime}\right)<(\alpha-\beta)$.

These assumptions simply state that ability's contribution in the production of extensive human capital is smaller in this economy, extensive human capital is not as ability-intensive in production. And that both production sectors do not differ as much in the use of inputs as in the formerly discussed economy. In other words, the schooling system allows relatively less able people to acquire extensive human capital at lower opportunity cost as compared to the benchmark economy. The economies are identical with respect to all other features.

The highly able benefit less from a (relative) increase in the price of extensive human capital than in the first economy. To see this, take the most able individual. In the first economy, his income would be $p_{E} E(\bar{a})$, while his clone in the second he would earn $p_{E} E^{\prime}(\bar{a})$, given identical prices $p_{E}$ in both economies. Therefore, the income difference between the two is $p_{E}\left(E(\bar{a})-E^{\prime}(\bar{a})\right)=p_{E}\left(\alpha-\alpha^{\prime}\right)(\bar{a}-s)$. Whenever Premise 3 holds, the individual belonging to the modified economy earns less, therefore also benefits less from an identical increase in $p_{E}$. Moreover, all individuals of ability higher than $s$ earn more in the first (more ability intensive) economy, if they produce extensive human capital. ${ }^{28}$

\footnotetext{
${ }^{27}$ The parameters of the benchmark economy are denoted without a prime.

${ }^{28}$ This is due to the technological specification. It is true irrespective of ability, if the schooling parameter is not related to $\alpha$, see below.
} 
Proposition 5 Assuming an identical human capital supply structure, inequality is lower in the economy in which the education technology uses ability less intensively (i.e. under Assumptions 1 and 2).

Proof. First note that $p_{E} / p_{I}$ is the same in both economies. Sticking with the notational convention of a prime, the difference in inequality becomes: $R^{\prime}-R=\left(\frac{p_{E}}{p_{I}}\right)\left[\frac{\int_{h \bar{a}}^{\bar{a}} E_{j}^{\prime} d a_{j}}{\int_{0}^{l \bar{a}} I_{j}^{\prime} d a_{j}}-\frac{\int_{h \bar{a}}^{\bar{a}} E_{j} d a_{j}}{\int_{0}^{l a \bar{a}} I_{j} d a_{j}}\right]<0$ since $E_{j}^{\prime}<E_{j}$ for all individuals in the high income group due to Premise 3 and Ass. 1 and conversely for the low income group due to Ass. 2. QED.

Note that it is also straightforward to show that $\frac{\partial R}{\partial \alpha}$ is positive as long as $\frac{(1+h)}{2} \bar{a}>s$ which is a slightly stronger requirement than Premise 3 , as it has to hold for any size of the high-ability group, $(1-h)$ (which means taking the $(1-h)$ of the population with highest ability). Just taking the most able individual $(h \rightarrow 1)$, the condition reduces to Premise 3 , as $\frac{2 \bar{a}}{2}>s$. If the technologies are such that the marginal productivities of ability and schooling are not inversely related (that is that, for example the technology for abstract knowledge is $E_{j}=\alpha a_{j E}+\zeta s_{E}$ where $\left.\zeta \neq 1-\alpha\right)$, then the results are valid even without need for a condition like Premise 3.

Proposition 6 Given an increase in $\gamma$ and hence the relative price of extensive human capital, the increase in inequality is larger in the economy in which extensive human capital production is more ability intensive.

Proof. Given identical price reactions, $\frac{\partial R^{\prime}}{\partial\left(p_{E} / p_{I}\right)}-\frac{\partial R}{\partial\left(p_{E} / p_{I}\right)}=\frac{\int_{h \bar{a}}^{\bar{a}} E_{j}^{\prime} d a_{j}}{\int_{0}^{\bar{l} \bar{a}} I_{j}^{\prime} d a_{j}}-$ $\frac{\int_{h \bar{a}}^{\bar{a}} E_{j} d a_{i}}{\int_{0}^{\bar{l}} I_{j} d a_{j}}<0$ due to Premise 3, and Ass. 1 and 2. QED.

\subsection{Discussion}

The difference in the education systems addressed in the preceding section is best illustrated considering a (stylized) example of US and German education systems: The US education system is best described by the notion of a "one-size-fits-all" system: Virtually every child goes to primary school, then high school, and eventually to college. As opposed to that, Germany is known for its dual track education system, in which individuals decide after 9 and 10 years whether to drop out of school and start a two to three year apprenticeship in a firm, which implies on the job instruction and the attendance of vocational schools for on average two days per week. If they do not drop out of school, individuals receive three more years of general classroom education before having the opportunity to either also do an apprenticeship or go to one of the two types of universities: General university, more aimed towards scientific curricula, or polytechnic (Fachhochschule), in which science is taught at a more applied level and where a total of one 
year of internships in private companies are obligatory. Although this description of the two systems is excessively rough in order to emphasize their differences, it seems to be in line with what can be observed in reality (see Harhoff and Kane (1997) for more information): In Germany, the percentage of the population without any kind of professional degree (university or vocational) is well below $10 \%$, while the numbers of university enrollment are far smaller than those of the US. On the other hand, in the US, the numbers of school drop-outs without professional degree is comparatively high. Moreover, there is virtually no systematic training and instruction scheme for those not continuing with college after completing high school.

What makes a big difference against the background of the previously described set-up is that in Germany individuals have more alternatives among which to choose their most preferred education attainment. This allows them to indulge more in their talents and preferences, so even at low levels of ability they can acquire knowledge they are particularly interested in, or to specialize in fields or occupations in which they have a comparative advantage. The term "specialists" might be somewhat misleading. What is transmitted in this more specialized educational alternatives is knowledge on a field, not just a specific task. Specific education therefore is not mere training of performing one assignment, but includes background knowledge of the respective field, as well. The perfect example for "specialization" is vocational training in Germany: A car mechanic is taught in such different fields as practical car engineering, metallurgy, metal working, electronics, mechanics, hydraulics, basic physics, English, basic management and law, and the like. Thus, the curriculum is wide, but nevertheless in a way specialized on the particular field of car engineering. This argument is also confirmed by empirical findings on the transferability of skills acquired during an apprenticeship, compare Clark (2000).

\section{Tentative Evidence and Possible Extensions}

\subsection{Some Evidence}

Empirical observations by and large support the view that differences in education and skills matter for inequality, and that differences in the education systems in part account for the cross country differences.

The conjecture that technological innovations are changing skill requirements and therefore the relative wage structure is largely consistent with empirical evidence. ${ }^{29}$ In an interindustry analysis using US micro data, Bartel and Sicherman (1999) report that technological change and wages are positively correlated and that the correlation between technological change and the education premium is significantly weakened once unobserved het-

\footnotetext{
${ }^{29}$ Compare Katz and Autor (1999) for an overview.
} 
erogeneity is controlled for. They suggest that this heterogeneity reflects innate ability, differences in schooling curricula, or the quality of schooling, thus establishing the link central to the model presented.

Card and Krueger (1992) present evidence that a higher schooling endowment as measured by pupil/teacher ratios, teacher qualification and the like has a positive impact on returns to education, and therefore income and (within group) earnings inequality. These results have recently been confirmed by Heckman et al. (1996).

The growing empirical literature on development accounting and human capital measurement corroborates the idea presented. Hanushek and Kimko (2000) and Woessmann (2000) find that differences in human capital quality as measured by results from direct tests of cognitive skills explain a large share of growth differences between countries. Hall and Jones (1999) document the importance of social capital like education culture for growth.

Evidence suggests that within-group inequality in Germany seems to be smaller in highly educated groups, which also happen to be high income groups, than in groups with little education. This refutes the argument that de-facto minimum wages or unionization were responsible for a compression of an otherwise also much more unequal income distribution. In contrast to the US and also most other European countries, the returns to education in Germany are roughly the same across all income groups and have been stable during the past 20 years. ${ }^{30}$ During the same period, the changes in the return to education differ substantially in the United States both across income groups and through time. ${ }^{31}$ Nickell and Layard (1999) find strong evidence that lower earnings inequality in some OECD countries, notably Germany, as compared to the US is a consequence of a more compressed distribution of human capital or "skills".

On the aggregate level, income inequality is strongly positively correlated with inequality in observable skills, as reported by the OECD (2000b, Fig. 4.13). Skills are measured by the outcomes of literacy tests evaluating the capability of understanding written text and performing quantitative exercises conducted for the OECD International Adult Literacy Survey (IALS). ${ }^{32}$ Freeman and Schettkat (2001) construct a data set for the US and Germany with comparable educational levels using disaggregated IALS data. They argue that skills, as measured by test scores, as well as wages are more compressed in Germany for comparable educational cohorts. ${ }^{33}$ Devroye and

\footnotetext{
${ }^{30}$ Telhado-Prereira and Silva-Martins (2000).

${ }^{31}$ Katz and Autor (1999).

${ }^{32}$ In particular, compare OECD (2000b), chapter 4. For a detailed description of the IALS, see OECD (2000b), Annex A.

${ }^{33}$ Freeman and Schettkat (2001) conclude that the wage compression is not caused by institutional wage setting and that therefore a dissolution of the latter would not boost employment. Moreover, they find that the pool of unemployed in Germany has skill test scores very similar to those of employed, in contrast to the US, where the unemployed perform significantly worse than the employed. This raises doubts about the conven-
} 
Freeman (2001) try to test the hypothesis that differences in earnings inequality can be explained by differences in the dispersion of skills across countries and look at disaggregated data from four OECD countries. They reject the hypothesis using a variance decomposition of earnings into skill variance and unexplained influences, and conclude that other phenomena explain the bulk of inequality differences. However, despite their negative conclusion, it seems that at least some of the inequality differences can be traced back to inequality in skills. In turn, this suggests that differences in the education system are at the heart of the matter, if comparable population structures are assumed. Moreover, so far the relation between skill dispersion and the change in earnings inequality has been neglected. ${ }^{34}$

In what follows, some evidence is presented, using aggregate data for 19 OECD countries on income inequality, several proxies for labor market institutions (like union coverage, employment protection, wage setting institutions etc.) and data on measured skills from the IALS. ${ }^{35}$ The questions to be addressed empirically are: (a) do proxies for the differences in education and education systems have explanatory power for earnings inequality? (b) Can they explain changes in inequality? (c) Are there other institutional differences or variables (like wage setting habits, employment protection, unemployment, changes in unemployment) that explain better the cross country differences in inequality and changes in inequality?

Due to the small sample size, simple OLS regressions are performed with only a constant and one (maximally two) explanatory variable. In order to be rather conservative with the conclusions from these experiments, the relevant criterion to discriminate between alternative models is the respective proportion of explained variation, $R^{2}{ }^{36}$ Eventually, non parametric tests for the correlation of the variables of interest are performed. ${ }^{37}$

The problem with an empirical strategy to test the theoretical model directly is that the modeled differences in education systems lead to similar predictions about observables. Since the model assumes identical population structures across countries, especially with respect to ability endowments and schooling, differences in the distribution of measurable skills must be

tional wisdom that wages in Germany are artificially compressed and through this cause unemployment.

${ }^{34}$ Devroye and Freeman (2001) only look at cross country differences in levels of inequality, not on the different changes of inequality and their determinants.

${ }^{35}$ The data are taken from OECD (1996, 2000a, 2000b), and Blanchard and Wolfers (2000), and are available from the author on request.

${ }^{36}$ It turns out that because of the small sample size, the hypothesis that the residuals are normally distributed must be rejected on the $10 \%$ level. Hence it would be a very strong requirement to impose normally distributed errors as is done implicitly if t-values are interpreted. Nevertheless, in the results, t-values are reported for additional information.

${ }^{37}$ Wilcoxon matched-pairs signed rank test and Kolmogorov-Smirnov test, checking the hypothesis that the distributions of changes in inequality of two groups separated by the educational inequality outcome are identical. 
attributed to different education systems. ${ }^{38}$ The explanatory variable used is therefore the share of the population scoring less than 3 in a scale from 1 to 5 , where 5 is the highest possible score, in internationally comparable tests of quantitative literacy undertaken on representative samples of individuals aged 16 to 65 : ialsq. ${ }^{39}$ A test score of 3 is considered to be the minimum requirement to "cope with the demands of everyday life and work in a complex, advanced society. It denotes roughly the skill level required for successful secondary school completion and college entry. It requires the ability to integrate several sources of information and solve more complex problems." (OECD, 2000b, p. xi). For the implications of the theoretical model to be tested empirically, this seems to be a relevant proxy, since it captures simultaneously the dispersion of skills and a reference to a level of skills after completing education. ${ }^{40}$

Some regression results for the level of total earnings inequality measured by the logged ratio of the 90th to the 10th percentile income for 1994(rt94), and of the change of earnings inequality 1984-1994 $(d r)$ and for males 1989$1995(\mathrm{~d} 5 \mathrm{rm})$ as dependent variables are presented in Figure 3. Besides the share of low skill test results (ialsq) and the mean of test results (ialsmean), also other institutional variables are included as regressors: ${ }^{41}$ Coordination of employers and unions in wage setting (coord), union density (uden), employment protection ( protect). In order to account for potential alternative explanations for cross country differences discussed in the literature, variables like the level of and the change in the aggregate capital stock ( $k 94$ and $d k)$ or unemployment rate $\left(u 1993\right.$ and $d u$ ) are included. ${ }^{42}$ Figures 4 and 5 present scatter plots of levels and changes in inequality on skill inequality,

\footnotetext{
${ }^{38}$ Empirical evidence supports the assertion of identical levels of schooling endowments: for OECD countries, public expenditure as portion of GDP and per capita is roughly comparable across countries, see OECD (2000a). In the example of US and Germany, spending on education in per capita terms as well as in terms of GDP or as share of total public spending is even higher in the US ((OECD, 2000a, pp. 43-50). Also, the ratio of teaching staff relative to students is higher in the US for all educational levels (OECD, 2000a, pp. 115-118), as is instruction time per year in total and in maths (OECD, 2000a, p. 237). The distribution of expenditure on education as of private and direct public payments are almost identical in the US and Germany (OECD, 2000a, p. 60). Moreover, Freeman and Schettkat (2001) report that the mean level of schooling (standard deviation of schooling) is 13.5 (2.35) years in the US compared to 12.9 (2.43) years in Germany, and that the per capita employment in the education sector in the US is higher than in Germany.

${ }^{39}$ The data are taken from the IALS results for quantitative literacy, OECD (2000b). Using the quantitative test reduces problems due to language proficiency differences related to differences in the ethnic structures of the countries under study.

${ }^{40}$ Note that only taking the dispersion like Devroye and Freeman (2001) is less adequate, since information on the structure of human capital in a country is lost which is relevant for the question of how technological or organizational shocks affect inequality.

${ }^{41}$ Mostly taken from Blanchard and Wolfers (2000).

${ }^{42}$ This is just a selection of the variables exhibiting the highest explanatory power. Results for a larger set of variables are available upon request.
} 
which clearly exhibiting a positive relationship. ${ }^{43}$

It would be bold to draw strong conclusions from these experiments. What can be claimed, though, is that differences in measurable skills across countries seem to matter, and especially differences in the equality of skill attainment. It is remarkable that these measures explain consistently more of the cross country variation in inequality and in particular inequality changes than other labor market institutions which have been studied in the literature. These findings are robust with respect to the use of the precise measure of skills, inequality and the choice of alternative institutional proxies used. The frequently mentioned argument that inequality and unemployment are two sides of the same coin is not supported by the data, at least not on the aggregate level. Finally, the hypothesis that two groups of countries, separated by inequality in test results (ialsq), share an identical development in inequality $(d r, d 5 r m)$, can be rejected on the $3 \%$ level using the Wilcoxon signed rank test. ${ }^{44}$ The separation can be inferred from Fig. 4 and 5, dividing the countries into two groups of equal size according to their ialsq-value. This result suggests that there is a strong systematic relationship between the change in earnings inequality and the dispersion of knowledge in the population, and supports the validity of the regression analysis.

\subsection{Related Results and Extensions to the Model}

Remark 1. Letting individuals produce both types of human capital simultaneously using any mix of the inputs at their disposal, instead of letting them produce only either one or the other, would not change the results: Due to the additive separability of the technologies, everybody would employ all his schooling endowment in acquiring intensive human capital and all ability in extensive human capital. The supply effect after a price change would be lost, but there would still be a unique equilibrium and the results on inequality would be qualitatively the same. All the effects can be generated with the possibility of simultaneous production, if a more general specification is chosen, in particular if inputs are essential in both technologies. This is done in an appendix available from the author, where all results are shown to be robust in a much more general framework.

Remark 2. An interesting experiment that one could think of would be to compare implications of the different education systems on equality with those on efficiency. In other words, it might be the case that a system in which ability is very important for human capital, total income generated

\footnotetext{
${ }^{43}$ There seems to be a negative relationship between test results and labor force participation in the sense that individuals scoring low (below 3) also participate less. However, this is a consistent pattern across all countries, not explaining cross country differences in the levels of participation of individuals. See OECD(2000b).

${ }^{44}$ Performing these nonparametric tests does not require any distributional assumptions on residuals.
} 
might be higher. Assume an education technology in which ability and schooling intensity are not related: $E_{j}=\alpha a_{j E}+\zeta s_{E}$ and $I_{j}=\beta a_{j I}+\xi s_{I}$. Then not only inequality is higher in an economy with, ceteris paribus, higher $\alpha$, but also total aggregate income is higher. Thus, the structure of the education system could be interpreted as the outcome of a policy decision, with the outcome depending on whether equality or efficiency has a higher weight in the government's objective function. ${ }^{45}$

Remark 3. With respect to the robustness of the results it is worthwhile mentioning that only the assumptions about the intensity of the production processes are crucial for the results. Arguably, the assumption that schooling is relatively more efficient in building up applied knowledge while abstract knowledge is more ability-intensive, seems not too far fetched and counterintuitive. With respect to the concept of inequality, the results are robust. The results is equivalent to the result for the wage ratio index used by Aghion, Howitt and Violante (2000) independent of whether one assumes that the most and the least able individuals were producing $I$ and $E$ simultaneously, or that individual $\bar{a}$ specializes in extensive human capital and the least able person is intensive human capital specialist or any other reasonable combination. It should be obvious, that also Gini-coefficients or Lorenz-curves would lead to the same results.

The implicit assumption of a uniform ability distribution instead of an arguably more realistic normal or lognormal distribution with more mass at some intermediate ability levels, is innocuous and does not change the qualitative results. The advantage of using the uniform is that it greatly facilitates the aggregation since the integrands do not have to be weighted by their density.

Finally, the form of the final output production function is not crucial for the results, as long as it pins down a unique input price ratio solving the model and allows for factor biased shocks, that is shocks that affect the relative input prices.

Remark 4. A point frequently made in the discussion about different inequality and unemployment outcomes in the US and Europe is that inequality in the US is just the counterpart of the German unemployment problem. However, as seen above, there is little empirical support for this. German unemployment is concentrated mainly among the older workforce, the former holders of nowadays outdated jobs, for example in steel, coal and shipbuilding industries, and not so much among the young. In contrast, the inequality in the US affects mostly the young who enter the labor market.

Remark 5. The result that the more specialized economy, Germany, should exhibit less inequality seems paradoxical at first sight. However, this reflects the idea that the schooling system allows for beneficial specialization,

\footnotetext{
${ }^{45}$ Note that this somewhat contradicts the evidence that on average countries with less inequality in skills also exhibit higher GDP per capita, see OECD (2000a, p. 80).
} 
that helps the less able to cultivate and exploit their relative advantages, therefore somewhat reducing the effects of naturally given heterogeneity. The schooling system allows also the less able to build abstract knowledge in certain fields, and therefore makes them less vulnerable to shocks biased towards abstract knowledge. In contrast, the "one-size-fits-all" US system contains less of this insurance effect for the less able. A feature not discussed in this framework is the potentially higher risk of the specialists in (some type of) extensive or intensive human capital to be hit by an adverse shock to their particular field. In the model this case is not considered since extensive and intensive human capital are homogeneous concepts. Impediments to switch within extensive human capital to other fields could cause unemployment due to obsoleteness of certain types of human capital. In other words, schooling may insure less able persons with respect to "abilitybiased" shocks in the form of increasing importance of extensive human

capital, but not against very asymmetric shocks, affecting particular facets of extensive human capital. It would be desirable to incorporate this feature in the model by specifying extensive human capital as within certain fields or sectors. Still, the basic argument of the model would hold, namely that the German system allows also less able individuals to build up extensive human capital, at least within some field if not in general.

\section{Conclusion}

This paper develops a model of human capital accumulation emphasizing individual heterogeneity with respect to innate ability, and multidimensionality of human capital, namely extensive and intensive human capital. In order to sell human capital on the labor market, both varieties have to be produced by individuals using their endowments of ability and schooling. Extensive human capital depends more heavily on innate ability. If, through some technological innovation or external shock, extensive human capital becomes more valuable for firms, individuals devote more resources to its production, to the cost of intensive human capital. The reward for ability is driven up, thus accentuating heterogeneity and enlarging inequality. If a schooling system weakens the direct link between extensive human capital and ability, the effect of an increase in the price of extensive human capital on inequality is also smaller.

The model is broadly in line with the empirical evidence on earnings inequality in industrialized countries, produces a supply reaction to relative demand shocks, and can account for very different experiences within the same framework.

From the policy perspective, the results are of practical relevance since, for example, the currently discussed reform of the German education system towards a more "americanized" system putting more weight on individual 
ability might very well have the side effect of increasing income inequality. 


\section{References}

[1] Abraham, Katharine G. and Susan N. Houseman (1993): "Earnings Inequality in Germany", NBER Working Paper 4541.

[2] Acemoglu, Daron (1998): "Why do Technologies Complement Skills? Directed Technical Change and Wage Inequality", Quarterly Journal of Economics CXIII, pp. 1055-1089.

[3] Acemoglu, Daron (1999): "Changes in Unemployment and Wage Inequality: An Alternative Theory and Some Evidence", American Economic Review 89(5), pp. 1259-1278.

[4] Aghion, Philippe, Eve Caroli and Cecilia García-Penalosa (1999): "Inequality and Economic Growth: The Perspective of the New Growth Theories", Journal of Economic Literature XXXVII, pp. 1615-1660.

[5] Aghion, Philippe, Peter Howitt and Giovanni Violante (2000): "General Purpose Technology and Within-Group Inequality", CEPR Discussion Paper 24\%, June.

[6] Bartel, Ann P. and Nachum Sicherman (1999): "Technological Change and Wages: An Interindustry Analysis", Journal of Political Economy $107(2)$, pp. 285-325.

[7] Ben-Porath, Yoram (1967): "The Production of Human Capital and the Life Cycle of Earnings", Journal of Political Economy 75(4), pp. 352-365.

[8] Berman, Eli, John Bound and Stephen Machin (1998): "Implications of Skill-Biased Technological Change: International Evidence", Quarterly Journal of Economics, CXIIV (November), pp. 1245-79.

[9] Blanchard, Olivier and Justin Wolfers (2000): "The Role of Shocks and Institutions in the Rise of European Unemployment: The Aggregate Evidence", Economic Journal, 110 (March), pp. C1-C33.

[10] Blanchflower, David G. and Matthew J. Slaughter (1999): "The Causes and Consquences of Changing Income Inequality", in A. Fishlow and K. Parker (eds.): Growing Apart: The Causes and Consequences of Global Wage Inequality, Council of Foreign Relations, New York.

[11] Card, David and Alan B. Krueger (1992): "Does School Quality Matter? Returns to Education and the Characteristics of Public Schools in the United States", Journal of Political Economy 100(1), pp. 1-40.

[12] Caselli, Francesco (1999): "Technological Revolutions", American Economic Review 89, pp. 78-102. 
[13] Clark, Damon (2000): "How Transferable is German Apprenticeship Training?", mimeo, University of Oxford and CEP, November.

[14] Devroye, Dan and Richard Freeman (2001): "Does Inequality in Skills Explain Inequality of Earnings Across Advanced Countries?", NBER Working Paper 8140, February.

[15] Freeman, Richard (1999): "The New Inequality in the United States", in A. Fishlow and K. Parker (eds.): Growing Apart: The Causes and Consequences of Global Wage Inequality, Council of Foreign Relations, New York.

[16] Freeman, Richard and Ronald Schettkat (2001): "Skill Compression, Wage Differentials and Employment: Germany vs. the US", mimeo, forthcoming in Oxford Economic Papers.

[17] Galor, Oded and Omer Moav (2000): "Ability-Biased Technological Transition and Economic Growth", Quarterly Journal of Economics, CXV, pp. 469-497.

[18] Gottschalk, Peter and Timothy M. Smeeding (1997): "Cross-National Comparisons of Earnings and Income Inequality", Journal of Economic Literature, 35 (June), pp. 633-687.

[19] Hall, Robert E. and Charles I. Jones (1999): "Why do some countries produce so much more output per worker than others", Quarterly Journal of Economics, CXIV(1), pp. 83-116.

[20] Hanushek, Eric and Dennis Kimko (2000): "Schooling, Labor Force Quality and the Growth of Nations", American Economic Review, 90(5), pp. 1184-1208.

[21] Harhoff, Dietmar and Thomas J. Kane (1997): "Is the German Apprenticeship System a Panacea for the US Labour Market?", Journal of Population Economics 10(2), pp. 171-196.

[22] Hassler, John and Jose Rodriguez-Mora (2000): "Intelligence, Social Mobility and Growth", American Economic Review, 90(4), pp. 888908.

[23] Heckman, James, Anne Layne-Farrar and Petra Todd (1996): "Human Capital Pricing Equations with an Application to Estimating the Effect of School Quality on Earnings", Review of Economics and Statistics 78(4), pp. 562-610.

[24] Helpman, Elhanan (1998): General Purpose Technologies and Economic Growth, MIT Press, Cambridge Massachusetts. 
[25] Helpman, Elhanan and Antonio Rangel (1998): "Adjusting to a New Technology: Experience and Training", NBER Working Paper 6551.

[26] Katz, Lawrence (1999): "Technological Change, Computerization and the Wage Structure", mimeo, Harvard University.

[27] Katz, Lawrence and David Autor (1999): "Changes in the Wage Structure and Earnings Inequality", in: O. Ashenfelter and D. Card (eds.): Handbook of Labor Economics, Vol. 3A, ch. 26, Elsevier, Amsterdam.

[28] Kim, Sunwoong (1989): "Labor Specialization and the Extent of the Market", Journal of Political Economy, 97(3), pp. 692-705.

[29] Lindbeck, Assar and Dennis Snower (2000): "Multitask Learning and the Reorganization of Work: From Tayloristic to Holistic Organization", Journal of Labor Economics 18(3), pp. 353-376.

[30] Machin, Stephen and John Van Reenen (1998): "Technology Changes in Skill Structure: Evidence from Seven OECD Countries", Quarterly Journal of Economics, CXIIV (November), pp. 1215-44.

[31] MasCollel, Andreu, Michael D. Whinston and Jerry R. Green (1995): Microeconomic Theory, Oxford University Press, New York.

[32] Moebius, Markus (2000): "The Evolution of Work", mimeo, MIT, September.

[33] Nickell, Stephen and Brian Bell (1996): "Changes in the Distribution of Wages and Unemployment in OECD Countries", American Economic Review 86(2), May, pp. 302-308.

[34] Nickell, Stephen (1997): "Unemployment and Labor Market Rigidities: Europe versus North America", Journal of Economic Perspectives 11(3), pp. 55-74.

[35] Nickell, Stephen and Richard Layard (1999): "Labour Market Institutions and Economic Performance", in O. Ashenfelter and D. Card (eds.): Handbook of Labor Economics, Vol. 3C, ch. 46, Elsevier, Amsterdam.

[36] OECD (1996): Employment Outlook, July 1996, OECD Paris.

[37] OECD (2000a): Education at a Glance, OECD Indicators: Education and Skills, Edition 2000, Organization for Economic Co-operation and Development, Paris.

[38] OECD (2000b): Literacy in the Information Age, OECD Paris. 
[39] Telhado-Pereira, Pedro and Pedro Silva-Martins (2000): "Does Education Reduce Wage Inequality? Evidence from Fifteen European Countries", IZA Discussion Paper 120, February.

[40] Theshmar, David and Mathias Thoenig (2000): "Creative Destruction and Firm Organizational Choice", Quarterly Journal of Economics CXV(4), pp. 1201-37.

[41] Woessmann, Ludger (2000): "Specifying Human Capital: A Review, some Extensions and Development Effects", Kiel Working Paper 1007, October, Kiel Institute of World Economics. 


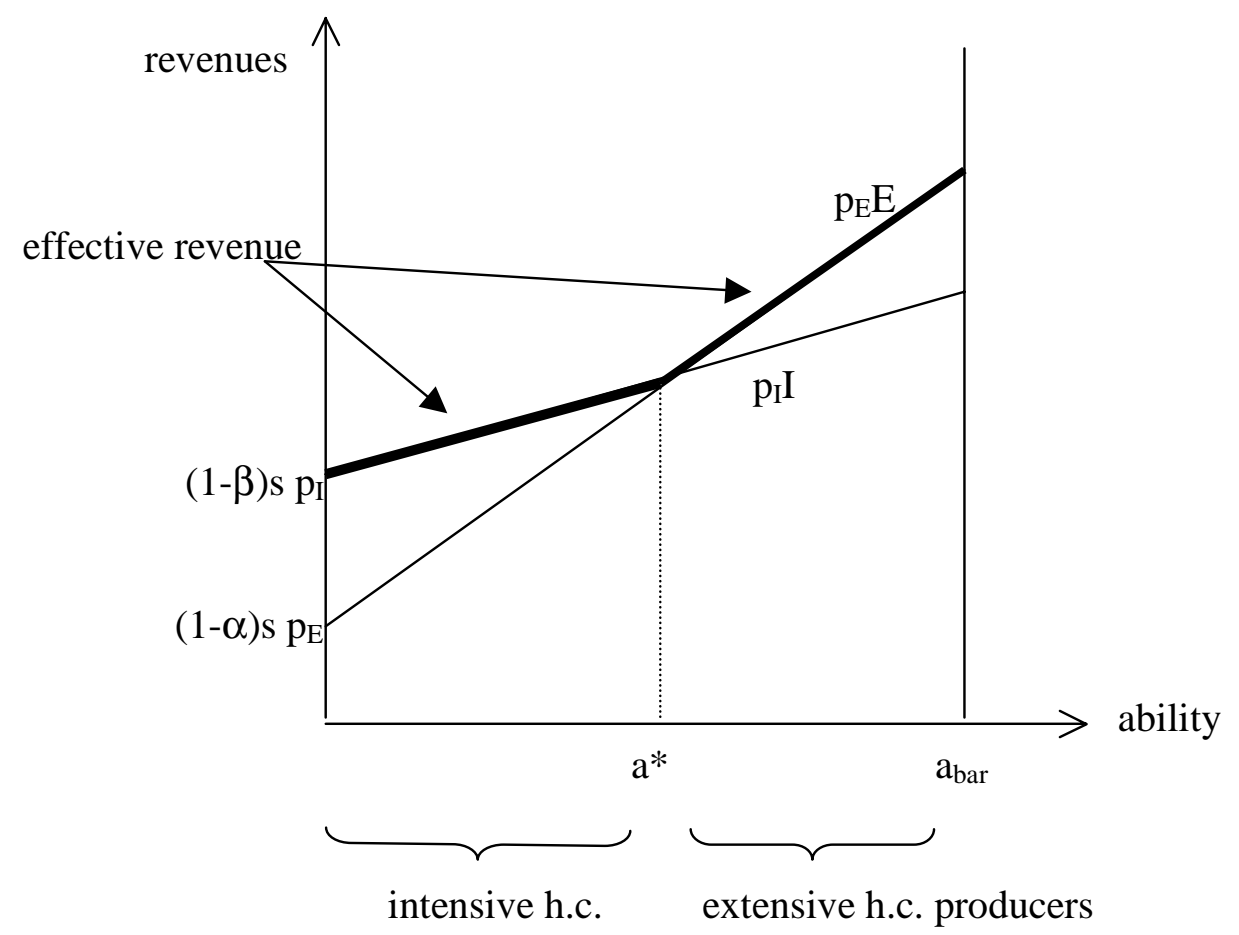

Figure 1: Income as function of ability 


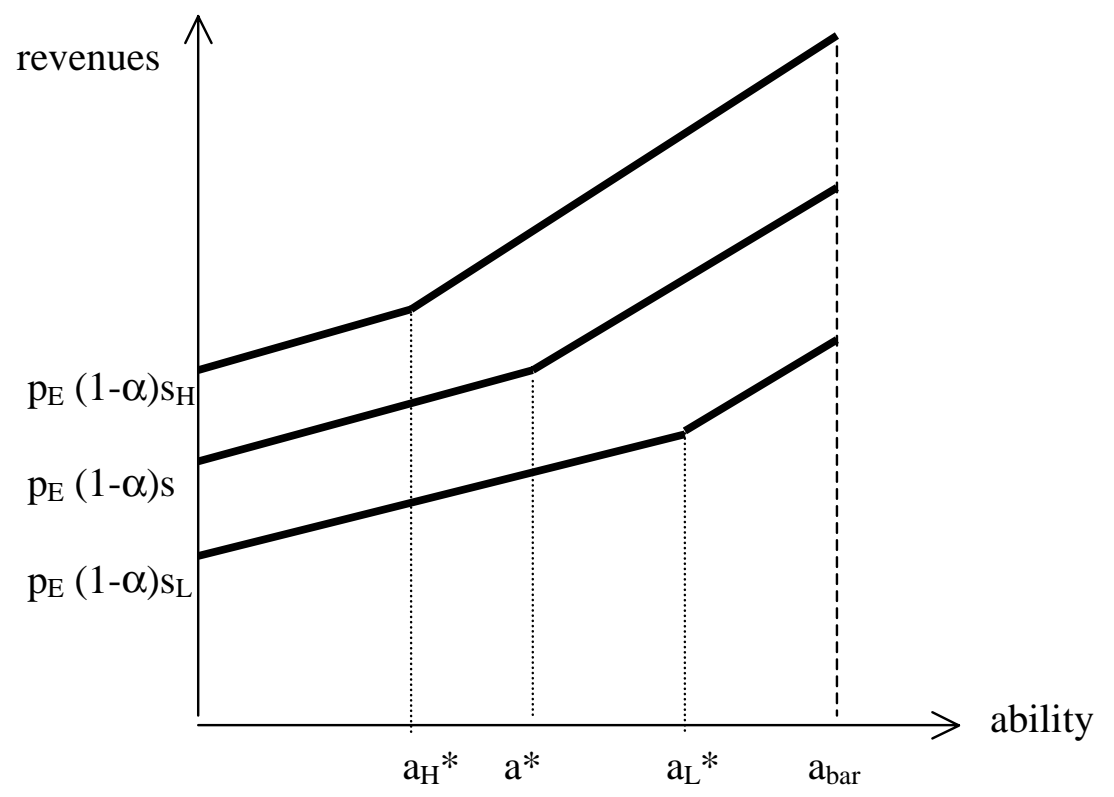

Figure 2: Incomes with heterogeneous schooling provision 


\begin{tabular}{|c|c|c|c|c|c|c|}
\hline \multirow{2}{*}{$\begin{array}{c}\text { Regressors for } \\
\text { (OLS, additional } \\
\text { to constant }) \\
\end{array}$} & \multicolumn{2}{|c|}{$r t 94$} & \multicolumn{2}{|c|}{$d r$} & \multicolumn{2}{|c|}{ D5rm } \\
\hline & $\begin{array}{c}\text { Coeff. } \\
(\mathrm{t})\end{array}$ & $\mathrm{R}^{2}$ & $\begin{array}{c}\text { Coeff } \\
(t)\end{array}$ & $\mathrm{R}^{2}$ & $\operatorname{Coeff}(t)$ & $\mathrm{R}^{2}$ \\
\hline ialsq & $\begin{array}{c}1.73 \\
(4.34)\end{array}$ & 0.61 & $\begin{array}{c}1.93 \\
(2.32)\end{array}$ & 0.31 & $\begin{array}{c}0.49 \\
(2.55)\end{array}$ & 0.39 \\
\hline ialsmean & $\begin{array}{c}-0.01 \\
(-3.77)\end{array}$ & 0.54 & $\begin{array}{c}-0.01 \\
(-2.11)\end{array}$ & 0.27 & $\begin{array}{c}-0.003 \\
(-2.69)\end{array}$ & 0.42 \\
\hline coord & $\begin{array}{c}0.11 \\
(3.87)\end{array}$ & 0.47 & $\begin{array}{c}0.17 \\
(2.63)\end{array}$ & 0.29 & $\begin{array}{c}0.02 \\
(0.08)\end{array}$ & 0.04 \\
\hline uden & $\begin{array}{l}-0.008 \\
(-3.29)\end{array}$ & 0.38 & $\begin{array}{c}-0.01 \\
(-1.60)\end{array}$ & 0.13 & $\begin{array}{c}-0.00 \\
(-0.29)\end{array}$ & 0.01 \\
\hline protect & $\begin{array}{c}-0.02 \\
(-1.77) \\
\end{array}$ & 0.18 & $\begin{array}{c}-0.04 \\
(-1.57) \\
\end{array}$ & 0.16 & $\begin{array}{c}0.01 \\
(0.97)\end{array}$ & 0.08 \\
\hline K94 & $\begin{array}{c}0.66 \\
(0.44) \\
\end{array}$ & 0.01 & & & & \\
\hline$d k$ & & & $\begin{array}{c}4.29 \\
(1.47)\end{array}$ & 0.11 & $\begin{array}{c}0.40 \\
(0.41)\end{array}$ & 0.01 \\
\hline U1993 & $\begin{array}{c}0.9 \\
(0.7) \\
\end{array}$ & 0.03 & & & & \\
\hline$d u$ & & & $\begin{array}{c}0.46 \\
(0.14)\end{array}$ & 0.00 & $\begin{array}{c}-0.33 \\
(-0.38)\end{array}$ & 0.01 \\
\hline
\end{tabular}

Figure 3: Regression Results (OLS with Constant and one Regressor) 


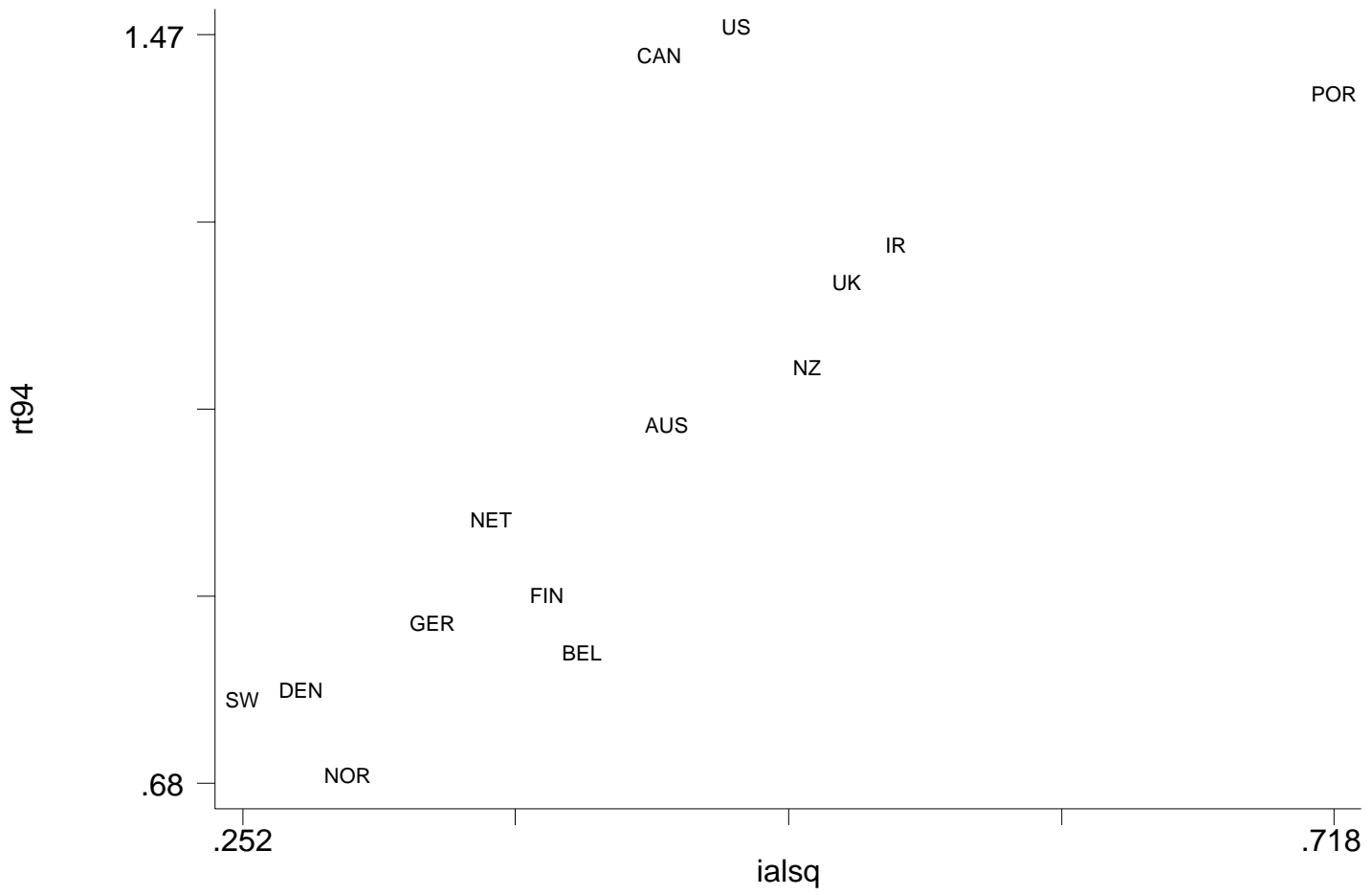

Figure 4: Inequality in skills (ialsq) and earnings (rt94) 


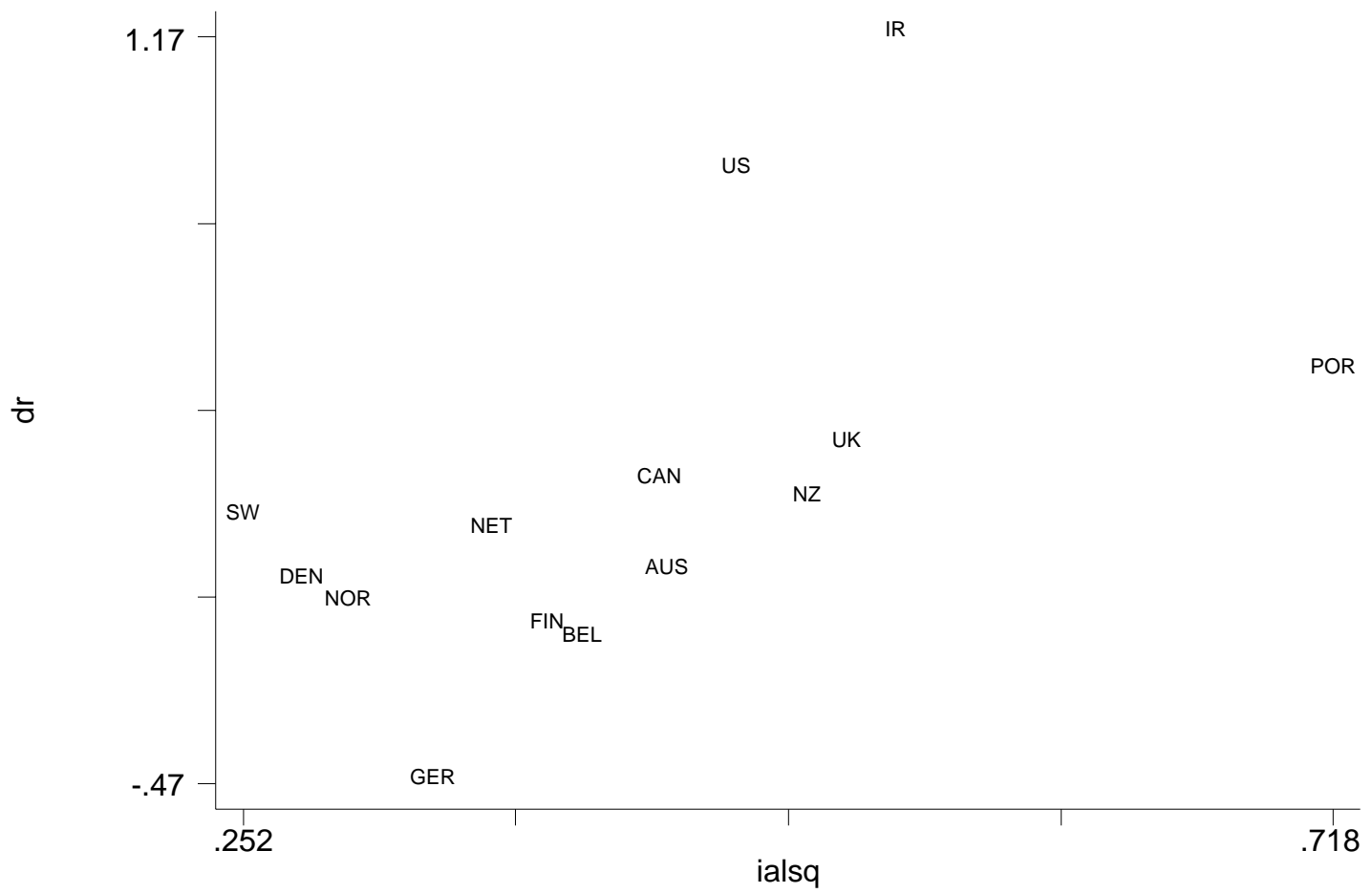

Figure 5: Inequality in skills (ialsq) and changes in earnings-inequality $(d r)$ 


\section{IZA Discussion Papers}

\section{No Author(s)}

231

G. Saint-Paul

232

E. Bardasi

M. Francesconi

233

C. Dustmann

C. M. Schmidt

234 R. Rotte

M. Steininger

235 W. Schnedler

236 R. Hujer

M. Caliendo

237 S. Klasen

I. Woolard

238 R. Euwals

A. Börsch-Supan

A. Eymann

239 F. Andersson

K. A. Konrad

240

W. Koeniger

241

W. Koeniger

242
G. Faggio
J. Konings

243

E. Brainerd

244

S. M. Fuess, Jr. M. Millea
Titel

Area

Date

The Economics of Human Cloning

5

$12 / 00$

The Effect of Non-Standard Employment on

5

$12 / 00$

Mental Health in Britain

The Wage Performance of Immigrant Women:

Full-Time Jobs, Part-Time Jobs, and the Role of

Selection

Sozioökonomische Determinanten extremistischer 3

$12 / 00$

Wahlerfolge in Deutschland: Das Beispiel der Europawahlen 1994 und 1999

Who gets the Reward? An Empirical Exploration

of Bonus Pay and Task Characteristics

Evaluation of Active Labour Market Policy:

6

$12 / 00$

Methodological Concepts and Empirical

Estimates

Surviving Unemployment without State Support:

3

$12 / 00$

South Africa

The Saving Behaviour of Two Person House-

5

$12 / 00$

holds: Evidence from Dutch Panel Data

Human Capital Investment and Globalization in

5

01/01

Extortionary States

Labor and Financial Market Interactions: The the UK 1969-95

Trade, Labor Market Rigidities, and GovernmentFinanced Technological Change

$01 / 01$

Job Creation, Job Destruction and Employment

4

$01 / 01$

Growth in Transition Countries in the 90's

Economic Reform and Mortality in the Former

4

$01 / 01$ Soviet Union: A Study of the Suicide Epidemic in the 1990s

Pay and Productivity in a Corporatist Economy: Evidence from Austria 
The Optimal Level and Composition of Retirement Benefit Systems

250 T. J. Hatton

J. G. Williamson

Demographic and Economic Pressure on

Emigration out of Africa

01/01

251 R. Yemtsov

Labor Markets, Inequality and Poverty in Georgia

$01 / 01$

252 R. Yemtsov

Inequality and Income Distribution in Georgia

$01 / 01$

253 R. Yemtsov

Living Standards and Economic Vulnerability in Turkey between 1987 and 1994 
263 N. Datta Gupta

N. Smith

264

C. Dustmann

265

M. Rosholm

M. Svarer

266 C. Dustmann

O. Kirchkamp

267 A. Newell

268

A. Newell

B. Reilly

269

H. Buddelmeyer

270

B. Augurzky

C. M. Schmidt

271 B. Augurzky

C. M. Schmidt

272 C. Belzil

J. Hansen

273 G. Saint-Paul

274

P. J. Pedersen

N. Smith

275 G. S. Epstein

T. Lecker

276

B. Amable

D. Gatti
Children and Career Interruptions:

The Family Gap in Denmark

5

$02 / 01$

Return Migration, Wage Differentials, and the 1

$02 / 01$

Optimal Migration Duration

Structurally Dependent Competing Risks

$02 / 01$

The Optimal Migration Duration and Activity

$02 / 01$

Choice after Re-migration

The Distribution of Wages in Transition Countries

4

$03 / 01$

The Gender Pay Gap in the Transition from

4

03/01

Communism: Some Empirical Evidence

Re-employment Dynamics of Disabled Workers

3

03/01

The Evaluation of Community-Based

6

$03 / 01$

Interventions: A Monte Carlo Study

The Propensity Score: A Means to An End

6

03/01

Heterogeneous Returns to Human Capital and

5

03/01

Dynamic Self-Selection

Distribution and Growth in an Economy with

5

$03 / 01$ Limited Needs

Unemployment Traps: Do Financial Dis-

3

$03 / 01$

incentives Matter?

Multi-Generation Model of Immigrant Earnings

03/01

Theory and Application

The Impact of Product Market Competition on

5

03/01 Employment and Wages 

national Integration

klund

S. Vroman

283 M. Hagedorn
A. Kaul

V. Reinthaler

Welfare Analysis in a Schumpeterian Growth to Internal Promotion for Young U.S. Men and Women Living Arrangements 

and the Rising Returns to Skill: US and France 1964-2000

293 D. Cobb-Clark T. F. Crossley

294 Š. Jurajda

N. Smith

L. Husted

297 J. C. van Ours J. Veenman

P. Cahuc

E. Wasmer
Gender, Comparative Advantage and Labor Market Activity in Immigrant Families Insurance Compensation on the Labor Market Histories of Displaced Workers

Individual Pay and Outside Options:

Intergenerational Transmissions and the Schoolto-Work transition of $2^{\text {nd }}$ Generation Immigrants

The Educational Attainment of Second Generation 1 Immigrants in The Netherlands

Returns to Education and Wage Equations and Subjective Well-Being The Role of Social Work

Economic and Social Perspectives of Immigrant 06/01 Children in Germany 
G. Abío

E. Berenguer

J. Gil

Accounting Perspective on Fiscal Policy and

2 Labour Market Trends in Spain

C. Patxot 